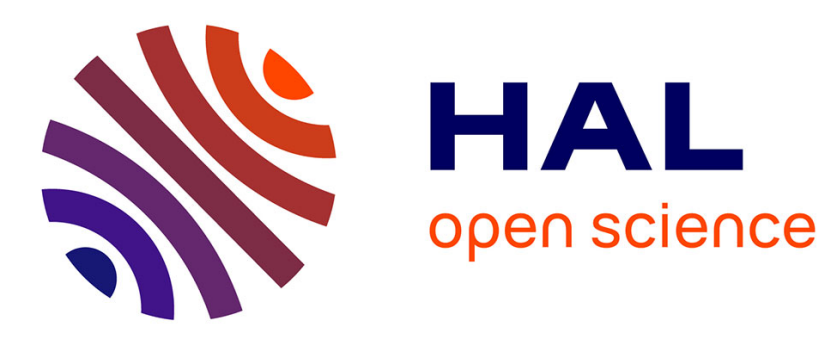

\title{
Interethnic Interactions: Expectancies, Emotions, and Behavioral Intentions
}

E. Ashby Plant, David A. Butz, Margarita Tartakovsky

\section{To cite this version:}

E. Ashby Plant, David A. Butz, Margarita Tartakovsky. Interethnic Interactions: Expectancies, Emotions, and Behavioral Intentions. Group Processes and Intergroup Relations, 2008, 11 (4), pp.555574. 10.1177/1368430208095827. hal-00571706

\section{HAL Id: hal-00571706 https://hal.science/hal-00571706}

Submitted on 1 Mar 2011

HAL is a multi-disciplinary open access archive for the deposit and dissemination of scientific research documents, whether they are published or not. The documents may come from teaching and research institutions in France or abroad, or from public or private research centers.
L'archive ouverte pluridisciplinaire HAL, est destinée au dépôt et à la diffusion de documents scientifiques de niveau recherche, publiés ou non, émanant des établissements d'enseignement et de recherche français ou étrangers, des laboratoires publics ou privés. 


\title{
Interethnic Interactions: Expectancies, Emotions, and Behavioral Intentions
}

\author{
E. Ashby Plant \\ Florida State University \\ David A. Butz \\ University of Massachusetts, Amherst \\ Margarita Tartakovsky \\ Texas A E $M$ University
}

\begin{abstract}
Two studies examine Hispanic and non-Hispanic White people's responses to interethnic interactions. Consistent with previous findings regarding White/Black interactions, participants who had negative expectations about intergroup interactions reported more anger and anxiety about interethnic interactions. These negative emotional responses, in turn, were associated with negative behavioral intentions such as the desire to avoid interethnic interactions and the externalization of blame if an interethnic interaction did not go well. Across the studies, White participants who were angry about interethnic interactions wanted to avoid these interactions, whereas anxiety was the key predictor of avoidance for the Hispanic participants. Results are discussed in terms of their implications for developing models of intergroup interactions and designing approaches to improve these interactions.
\end{abstract}

KEYWORDS attitudes toward Hispanics, attitudes toward Whites, avoidance, Hispanic, intergroup interactions

As ethnic and racial diversity in the USA continues to increase, it is important to understand the factors that influence the quality of intergroup interactions. Much previous research on intergroup interactions has focused on factors that influence the course and nature of interactions between White and Black people (Britt, Boniecki, Vescio, Biernat, \& Brown, 1996; Devine, Evett, \& Vasquez-Suson, 1996; Plant, 2004; Plant \& Butz, 2006; Plant \& Devine, 2003; Shelton, 2003). This work has provided much insight into these types of interactions and the factors that influence their quality. Such a concentration likely stems in part from the fact that Blacks were at one time the most populous racial/ethnic minority group in the USA. Recent

\footnotetext{
$\overline{\text { Author's note }}$

Address correspondence to E. Ashby Plant, Department of Psychology, Florida State University, 1107 W Call St., PO Box 3064301 Tallahassee, FL 32306-4301 [email: plant@psy.fsu.edu]
} 
U.S. Census Bureau statistics, however, indicate that Hispanics (i.e. people of Latin American or Spanish decent) have now emerged as the largest minority group in the USA (U.S. Census Bureau, 2005). The empirical literature on interactions between Whites and Hispanics has not grown in proportion to the Hispanic population, with relatively few published studies directly examining White people's responses toward Hispanic people or Hispanic people's responses toward White people (Jackson et al., 1996; Marin, 1984; White \& Sedlacek, 1987).

In response to this gap in the literature, the current study examines interethnic interactions between Hispanic people and non-Hispanic White people, who for the sake of brevity will be referred to as White people. Specifically, this research explores the factors that influence emotional responses to such interethnic interactions as well as people's desire to avoid these interactions. In addition, this study explores whether a recently developed model of interracial interactions (Butz \& Plant, 2006; Plant \& Butz, 2006; Plant \& Devine, 2003) can be applied to Hispanic/White interethnic interactions.

The literature on intergroup attitudes suggests that there may be some important differences between Black/White interactions and Hispanic/ White interactions. In general, Hispanic people are more likely to report interethnic friendships than White and Black people (Joyner \& Kao, 2000), and White people's attitudes toward Hispanics tend to be more positive than their attitudes toward Black people (White \& Sedlacek, 1987). Further, White people hold different stereotypes about these two groups. For example, Jackson et al. (1996) found that White people's perceptions of Black people focused on traits such as rebellious, noisy, and angry, whereas their perceptions of Hispanic people focused on Hispanics as being underprivileged, poor, and less educated than Whites. Jackson and colleagues argued that these differential perceptions result in fear associated with Black people and blame directed at Hispanics. Further, Cottrell and Neuberg (2005) showed that U.S. Whites perceived Mexican Americans as the highest economic threat compared with other outgroups, which was particularly likely to evoke anger. Together, these findings suggest that White people may be more likely to respond with anger toward Hispanic people and more likely to respond with anxiety or fear toward Black people.

Mackie, Devos, and Smith (2000) argued that people who perceive their ingroup as strong are more likely to experience anger (as opposed to anxiety) directed at outgroups than those who perceive their ingroup as weak. Accordingly, members of high-power majority groups (e.g. Whites in the USA) may experience more anger directed at racial/ethnic outgroups (e.g. Hispanics) than racial/ethnic outgroups direct toward majority groups (also see Ridgeway \& Johnson, 1990). Because low-status group members are not in a position to challenge high-status group members, they tend to experience more submissive emotional reactions instead of anger (see Keltner, Gruenfeld, \& Anderson, 2003). Consistent with this idea, Mackie et al. (2000) argued that people who perceive their ingroup as weak primarily experience fear-related emotional reactions (i.e. anxiety) as opposed to anger in response to powerful outgroups, although their findings did not support this prediction. However, their work focused on groups that differed in their attitudes (e.g. preferred punishment severity for illegal drug use) as opposed to ethnic groups. It is possible that the power differential experienced by people based on ethnic group membership is more salient and long-standing than perceptions of power based on attitudes and, as a result, may have a stronger impact on people's emotional experiences. Therefore, it is possible that members of low-status racial/ethnic groups, including Hispanics, may respond to majority group members with anxiety rather than anger.

The possibility that people experience different emotional reactions toward distinct racial/ethnic outgroups (see Cottrell \& Neuberg, 2005) has important implications for expanding the scope of theorizing on intergroup relations. Much prior theorizing on intergroup relations has focused on anxiety (Gudykunst, 1993; Plant, 2004; Plant \& Devine, 2003; Stephan \& Stephan, 1985, 1989, 2000). However, recent theorizing 
has begun to expand the focus to consider the causes and consequences of anger in intergroup interactions (Butz \& Plant, 2006; Mackie et al., 2000). For example, Butz and Plant (2006; Plant \& Butz, 2006) expanded upon previous models of interracial interactions that focused on the role of negative expectancies in predicting interracial negative emotional responses (Plant \& Devine, 2003; Vorauer \& Kumhyr, 2001; Vorauer, Main, \& O'Connell, 1998) and argued that anxiety and anger may be differentially associated with specific types of negative expectations regarding interracial interactions.

Butz and Plant (2006) proposed that expectations centered on one's ability to perform well in interracial interactions (i.e. self-efficacy expectancies) determine people's anxious and avoidant reactions. By contrast, anger and hostile responses in interracial interactions stem from perceiving outgroup members as not open to interracial interactions (i.e. negative response expectancies). In considering intergroup interactions, negative response expectancies reflect people's concern that even if they behave in a nonbiased, friendly manner, the interaction will not go well because their interaction partner is not open to the interaction and expects racial bias from them, a concept similar to Vorauer and colleagues' construct of meta-stereotyping (Vorauer \& Kumhyr, 2001; Vorauer et al., 1998). Frey and Tropp (2006) recently argued that interracial interactions may be particularly distressing because rejection by racial or ethnic outgroup members may be perceived as both a personal rejection and the rejection of one's racial or ethnic group. Consistent with this argument, Butz and Plant (2006) demonstrated that White participants reported more anger when they anticipated that an interracial (i.e. Black) compared with an intraracial (i.e. White) interaction partner was not open to an interpersonal interaction.

\section{The current study}

The current study expands upon previous research on interracial interactions to examine whether the model developed to understand interactions between Black and White people
(Butz \& Plant, 2006; Plant, 2004; Plant \& Butz, 2006; Plant \& Devine, 2003) captures the factors involved in interactions between Hispanic people and White people. Across two studies, we examined whether people's expectancies about the course of interethnic interactions influenced their anxiety and anger regarding such interactions and whether these emotional reactions influence their desire to avoid such interactions. Our hope with this study was that insight into the factors that contribute to the quality of interethnic interactions will aid in the development of theoretically driven interventions to improve interethnic relations.

Study 1 examined White participants' responses to interactions with Hispanics and Hispanic participants' responses to interactions with White people. Study 2 manipulated Hispanic and White participants' response expectancies regarding an upcoming interethnic interaction and examined the implications of these expectancies for their affective responses and behavioral intentions regarding the interaction. In general, we anticipated that the responses across the studies would be consistent with the model of intergroup relations and, thus, would provide evidence that this model generalizes beyond White/Black interactions (Butz \& Plant, 2006; Plant \& Butz, 2006; Plant \& Devine, 2003). Specifically, we predicted that anxiety regarding interethnic interactions would result from concerns that one does not have the skills necessary to engage in pleasant interethnic interactions. By contrast, anger would result from the perception that ethnic outgroup members are not open to intergroup interactions.

However, we anticipated that there would be some differences between how White people responded to Hispanics and how Hispanics responded to White people. Based on previous theorizing regarding status differences in intergroup emotions (Mackie et al., 2000; Ridgeway \& Johnson, 1990), we anticipated that White participants compared with Hispanic participants would experience more anger regarding the interethnic interaction. In addition, we predicted that White people's anger toward Hispanics would result in a desire to avoid interethnic interactions for White people. Although 
avoidance of interracial interactions is typically linked to anxiety (Plant \& Devine, 2003; Stephan \& Stephan, 1985), relatively little work has directly examined the link between anger and intergroup avoidance. One exception, Zinner, Brodish, Devine, and Harmon-Jones (2008), found that anger regarding an upcoming interracial interaction resulted in relative right frontal cortical activity, which is a motivational withdraw response. They argued that acting on anger in interracial interactions may not be perceived as appropriate or justifiable, particularly when the outgroup member is a minority group member. Therefore, anger in the context of intergroup interactions may motivate White people to withdraw from the aversive situation. Together, this previous work suggests that both anger and anxiety may determine people's avoidance of interethnic interactions but that anger may be particularly important in predicting White people's avoidance of Hispanic people.

\section{Study 1}

The first study explored White and Hispanic participants' self-reported responses to interethnic interactions. We assessed the positivity of previous experiences with the other ethnic group in the recent past as well as in their youth. Previous findings indicate that the quality of previous contact with outgroup members is an important predictor of intergroup attitudes (Brown \& Hewstone, 2005; Eller \& Abrams, 2003), and is specifically associated with more positive expectations about the outcomes of interracial interactions (Plant \& Devine, 2003). Therefore, we anticipated that more positive previous interethnic experiences would be associated with more positive self-efficacy and response expectancies regarding interethnic interactions.

We also developed scales to assess participants' attitudes toward the outgroup. Participants with more negative attitudes toward outgroup members were expected to be more negatively inclined toward interethnic interactions, which would likely result in more negative expectancies about the interaction and possibly more negative affect and a stronger desire to avoid interethnic interactions. In addition, drawing from measures used in previous work examining interracial interactions, we asked participants about their self-efficacy expectancies and response expectancies regarding interethnic interactions and their anxiety and anger regarding these interactions. Finally, we measured participants' desire to avoid interactions with outgroup members.

\section{Method}

Participants and procedure Participants were 49 (36 women) White and 53 (36 women) Hispanic introductory psychology students who volunteered to take part in the study as partial fulfillment of a course requirement ( $M$ age $=18.43, S D=.80)$. Participants came to a classroom in group sessions of 5-15 participants and, after signing a consent form, completed a series of questionnaires asking about their responses to interethnic interactions. Participants were asked to take one of the two versions of the questionnaire depending on whether they identified as Hispanic or non-Hispanic. ${ }^{1}$ They were assured that their responses to the questionnaires would remain anonymous.

Materials There were two versions of the questionnaire packet. White participants completed questions related to their interactions with Hispanic people and Hispanic participants completed questions related to their interactions with White people. The packet included items assessing the quality of participants' previous contact with the target outgroup, their attitudes about the outgroup, their self-efficacy expectancies and response expectancies regarding interactions with the outgroup, their anxiety and anger resulting from such interactions, and their desire to avoid interactions with the target outgroup.

In order to assess quality of previous contact, self-efficacy and response expectancies, anxiety, anger, and desire to avoid interethnic interactions, the Social Interactions Questionnaire (SIQ; Plant \& Devine, 2003) was modified to assess Hispanic/White interactions and additional items tapping into the distinction between self-efficacy and response expectancies were added (see Appendix for scale items). For 
ease of presentation and consistency, except for the attitude measures, we present items from the scales that the White participants completed about responses toward Hispanics. Hispanic participants' items were identical but asked about interactions with White people. Participants rated the items on a scale from 1 (strongly disagree) to 7 (strongly agree). Items assessing each construct were averaged to create indices. Three items were used to assess quality of contact where higher scores indicated more positive previous contact $(\alpha=.78) .{ }^{2}$ Six items assessed self-efficacy expectancies $(\alpha=.71)$ and six items assessed response expectancies $(\alpha=.74)$, with higher scores indicating negative expectancies in both cases. Five items assessed anxiety about interethnic interactions $(\alpha=.74)$ and three items assessed anger $(\alpha=.70)$ with higher scores in both cases indicating more emotion. Finally, five items were averaged to assess the desire to avoid interethnic interactions, with higher scores indicating more of a desire to avoid $(\alpha=.83)$.

Attitude measures were created that assessed Hispanic people's attitudes toward White nonHispanics and White non-Hispanic people's attitudes toward Hispanics. Some of the items on these measures were taken from other attitude scales (e.g. 'I would rather not have Hispanics live in the same apartment building that I live in'; Brigham, 1993). Other items were created for these measures and were designed to tap into issues of particular relevance for these groups. All items were rated on a scale from 1 (strongly disagree) to 7 (strongly agree).
For the White's attitudes toward Hispanics, some items were included that tapped into attitudes about Hispanic immigration and assimilation (e.g. 'Stricter laws should be established to control Hispanic immigration'). A few items that reduced the reliability of the measure were dropped and this resulted in a 29-item index that was highly reliable $(\alpha=.96)$. To assess Hispanic's attitudes toward Whites, we created items that explore perceptions of White people's bias toward Hispanics and preference for interacting with Hispanics (e.g. 'Many Whites don't understand the Hispanic culture'). Once again, items that reduced the reliability of the scale were dropped. This resulted in an index with 18 items, which was highly reliable $(\alpha=.96)$. The items from the final version of each of these attitude scales can be found in the Appendix. For the analyses, the participants' scores on the attitude scales were $z$-scored and then combined into a single variable, which we refer to as attitude.

\section{Results}

The correlations between the indices are presented separately for the Hispanic and White non-Hispanic participants in Table 1. In general, the correlations were consistent with previous studies (Butz \& Plant, 2006; Plant, 2004) and were quite similar between the two ethnic groups both in direction and magnitude. More negative attitudes and less positive previous intergroup contact were related to more negative expectancies, negative emotional responses, and a greater desire to avoid interethnic interactions.

Table 1. Intercorrelations between measures (Study 1) for White participants and Hispanic participants separately

\begin{tabular}{lccccccc}
\hline & 1 & 2 & 3 & \multicolumn{1}{c}{4} & \multicolumn{1}{c}{5} & 6 & 7 \\
\hline 1. Positive contact & - & -.66 & -.58 & -.50 & -.57 & -.46 & -.75 \\
2. Attitude & -.37 & - & .72 & .71 & .60 & .60 & .71 \\
3. Efficacy expectancies & -.66 & .68 & - & .74 & .78 & .67 & .74 \\
4. Response expectancies & -.66 & .61 & .77 & - & .68 & .72 & .68 \\
5. Anxiety & -.53 & .54 & .65 & .53 & - & .61 & .65 \\
6. Anger & -.52 & .59 & .74 & .62 & .57 & - & .76 \\
7. Avoidance & -.62 & .58 & .68 & .59 & .73 & .59 & - \\
\hline
\end{tabular}

Note: White non-Hispanic participants' correlations are on top half of table and Hispanic participants' correlations are in italics on bottom half of table. All correlations were significant at the .05 level. 
More negative expectancies were related to more negative emotional reactions and greater avoidance. Finally, more negative emotional responses were related to a stronger desire to avoid interethnic interactions. The magnitude of these correlations does raise the question of multicollinearity, which may influence the likelihood of obtaining significant independent effects in the regression analyses.

Participants' responses to the indices were next analyzed using hierarchical regression to test specific predictions regarding the relationships between the variables. All continuous measures were $z$-scored for the analyses. Consistent with previous work, analyses were conducted in three phases in order to test the specific predictions delineated in the model (see Plant \& Devine, 2003). In the first phase, we examined the implications of ethnicity, contact with outgroup members, and attitudes toward outgroup members for self-efficacy expectancies and response expectancies regarding interethnic interactions. In the second phase, we examined the influence of ethnicity, contact, and attitudes, as well as efficacy and response expectancies for participants' anxiety and anger when interacting with outgroup members. In the final phase, we examined the implications of ethnicity, contact, attitudes, expectancies, and affect for participants' desire to avoid interethnic interactions. At each phase, we also examined the interactions between ethnicity and each of the predictors. For simplicity, the final versions of the analyses only included those interactions that were significant. The path models for the White and Hispanic participants can be found in Figure 1.

It would have also been possible to analyze the current data using structural equation modeling, and employing this approach revealed that the

White Participants

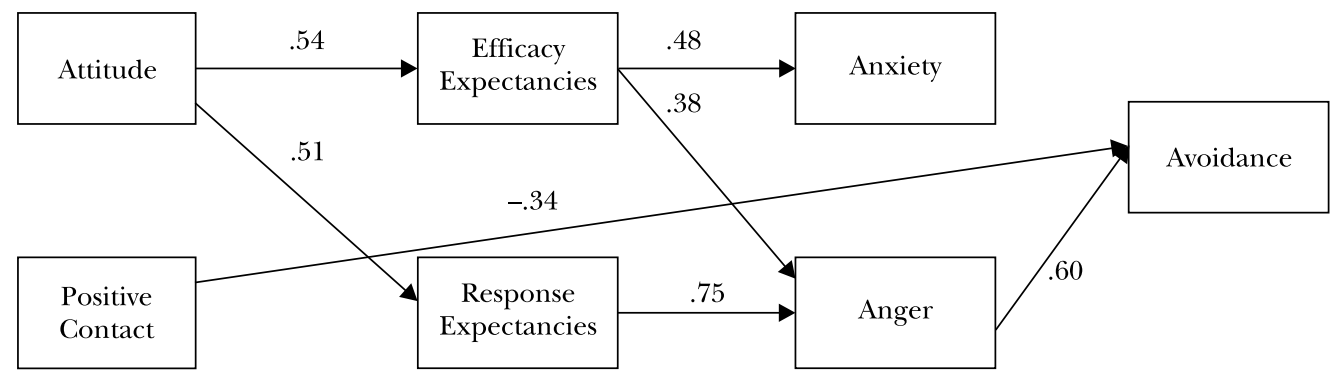

Hispanic Participants

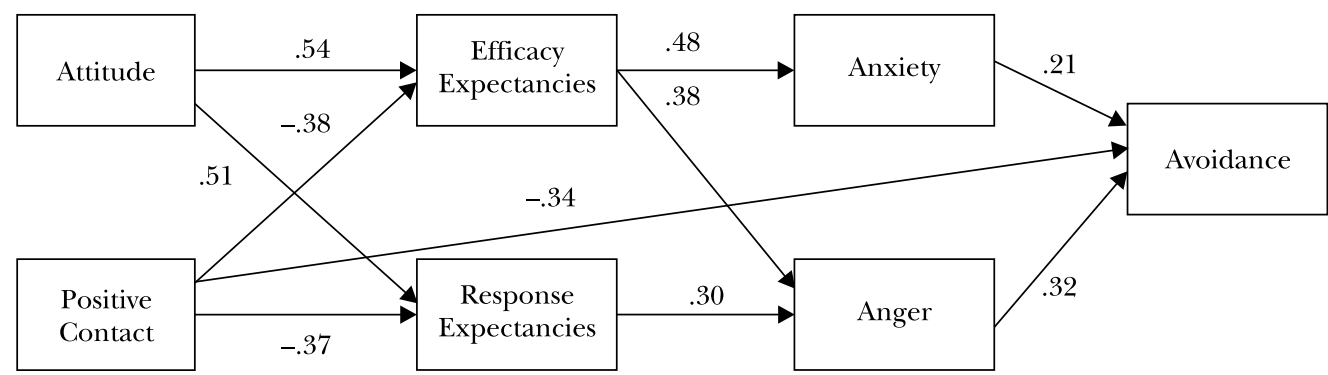

Figure 1. White and Hispanic participants' responses to interethnic interactions (Study 1). All included paths were significant at $p<.05$. 
findings were reasonable and highly similar to the current findings (the model for the White and Hispanic samples fit the data reasonably well; both GFIs > .90, RMRs <.08). However, MacCallum, Browne, and Sugawara (1996) estimated that $>500$ participants would be needed to achieve a desired power of .80 and conduct the recommended tests of model fit for this particular model using a covariance structure modeling approach. Therefore, we felt that we were underpowered for a structural equation modeling approach and present the findings of the regression analyses. Regression analyses also provided a more straightforward approach to test for the predicted differences in the White and Hispanic participants' responses.

Phase 1 The analysis of self-efficacy expectancies indicated that more negative attitudes toward outgroup members were related to more negative self-efficacy expectancies about interacting with that outgroup, $F(1,98)=47.94$, $p<.001, \beta=.54$. In addition, more positive previous contact was related to less negative selfefficacy expectancies, $F(1,98)=20.33, p<.001$, $\beta=-.36$. However, this main effect was qualified by an interaction between contact and ethnicity, $F(1,97)=7.90, p<.005, \beta=-.24$. Simple slopes analyses revealed that the effect of contact on self-efficacy was significant for the Hispanic participants, $F(1,97)=24.89, p<.001, \beta=-.39$, but not White participants, $F<1$.

The analysis of response expectancies revealed an effect of attitudes, which indicated that more negative attitudes toward outgroup members were related to more negative response expectancies about the openness of outgroup members to interethnic interactions, $F(1,98)=35.23$, $p<.001, \beta=.50$. In addition, more positive previous contact was related to less negative response expectancies, $F(1,98)=15.55, p<.001$, $\beta=-.34$. However, this main effect was qualified by an interaction between contact and ethnicity, $F(1,97)=8.29, p<.006, \beta=-.26$. Similar to the effect for self-efficacy, simple slopes analyses revealed that quality of contact was related to Hispanic participants' response expectancies, $F(1,97)=19.59, p<.001, \beta=-.37$, but not White participants' response expectancies, $F<1$.
Phase 2 The analysis of anxiety revealed that, consistent with the model, participants' selfefficacy expectancies were associated with anxiety, such that more negative self-efficacy expectancies were associated with more anticipated anxiety in interethnic interactions, $F(1,96)=15.64$, $p<.001, \beta=.48$. Also consistent with the model, response expectancies were not related to anxiety, $F=.40$, ns.

The analysis of anger revealed a main effect of ethnicity, such that the White participants reported that they would find interethnic interactions more anger-provoking than Hispanic participants, $F(1,96)=3.95, p=.05, \beta=-.15$. The analysis also revealed a main effect of self-efficacy that was contrary to the model, participants with more negative self-efficacy expectancies reported more anger regarding interethnic interactions, $F(1,96)=9.75, p<.003$, $\beta=.38$. There was also the predicted main effect of response expectancies, with more negative response expectancies associated with more anger regarding interethnic interactions, $F(1$, $96)=5.93, p<.03, \beta=.27$. In addition, the analysis revealed a significant interaction between ethnicity and response expectancies, $\beta=.62$, $F(1,94)=4.59, p<.04, \beta=-.34$. Simple slopes analyses indicated that response expectancies were a stronger predictor of White participants' anger, $\beta=.75$ than Hispanic participants' anger, $\beta=.30$. It should be noted, however, that response expectancies were a strong predictor for both groups of participants.

Phase 3 The final phase of the analysis examined participants' desire to avoid interethnic interactions. There was a strong effect of quality of previous contact, which indicated that more positive previous contact resulted in less of a desire to avoid interethnic interactions, $F(1$, $94)=20.93, p=.001, \beta=-.34$. The analysis also revealed an effect of anxiety, which indicated that greater anxiety about interethnic interactions was associated with more of a desire to avoid these interactions, $F(1,94)=6.82, p<.02, \beta=.21$. In addition, there was an effect of anger, such that more anger in response to interethnic interactions was associated with more of a desire to avoid these interactions, $F(1,94)=18.15$, 
$p<.001, \beta=.35$. The analyses also revealed an interaction between anxiety and ethnicity, $F(1$, $92)=5.12, p<.03, \beta=.20$, and an interaction between anger and ethnicity, $F(1,92)=3.94$, $p=.05, \beta=-.18$.

For anxiety, simple slopes analyses indicated that anxiety was related to a greater desire to avoid interethnic interactions for the Hispanic participants, $F(1,92)=6.70, p<.02, \beta=.21$, but not for the White participants, $F<1$. By contrast, for anger, simple slopes analyses indicated that anger was related to a greater desire to avoid interethnic interactions for both White and Hispanic participants but the relationship was stronger for the White participants $(\beta=.60)$ than for the Hispanic participants $(\beta=.32)$.

\section{Discussion}

The findings from the current study were generally consistent with expectations with a few interesting exceptions. Consistent with previous work examining Black/White interactions, participants with more positive previous contact with outgroup members had more positive expectations about their ability to respond in a positive manner in interethnic interactions, although this was only the case for Hispanic participants (Plant, 2004; Plant \& Devine, 2003). For White participants, their perceived selfefficacy for interactions with Hispanic people was unrelated to the amount of positive previous contact they had. Similarly, contact was related to Hispanic but not White participants' response expectancies for interethnic interactions. This finding indicates that White people's perceptions of whether Hispanic people are open to interethnic interactions were not related to the quality of actual contact they had with outgroup members and were therefore likely not based on actual negative responses by Hispanic people.

In contrast to contact, negative attitudes toward the outgroup were related to both more negative self-efficacy expectancies and more negative response expectancies for both Hispanic and White participants. These findings suggest that people with negative outgroup attitudes are likely to approach interethnic interactions with the expectation that they will go poorly. It is worth noting that attitude did not interact with the ethnicity of the participants even though the attitude measures were different for the ethnic groups. This suggests that even though the two attitude scales used different items, they were tapping into a similar construct.

For both Hispanic and White participants, consistent with our model and predictions, anxiety regarding interethnic interactions was related to the participants' concern that they did not have the ability to perform well in the interaction, but not to their perception that outgroup members were open to them. Also as predicted, the White participants reported more anger regarding interethnic interactions than Hispanic participants.

The participants' anger regarding interethnic interactions was related to their concern that outgroup members would reject them, which is highly consistent with Butz and Plant's (2006) findings regarding White/Black interactions (also see Vorauer \& Kumhyr, 2001; Vorauer et al., 1998). However, this effect was stronger among the White participants than the Hispanic participants. In order to more directly test whether perceptions of the openness of outgroup members predicted intergroup anger for both White and Hispanic participants, Study 2 manipulated response expectancies.

Finally, anxiety predicted the desire to avoid interethnic interactions for Hispanic participants but, consistent with predictions, anger was predictive of avoidance for White participants. These findings indicate that although anger is often assumed to be distinctly approach-related (Harmon-Jones, 2003; Mackie et al., 2000), in some intergroup contexts it may also precipitate avoidance-related inclinations. For example, in interethnic interactions, acting out in response to anger would violate social sanctions discouraging ethnic bias and, for some, personal beliefs that outgroup bias is wrong (Plant \& Devine, 1998). In these instances, anger may motivate people to withdraw from the aversive situation (i.e. the interethnic interaction), a possibility that we further explore in Study 2.

\section{Study 2}

Although the findings from the first study provided some insight into the relationships between the different responses to interethnic 
interactions, because the design was correlational, it is difficult to make claims about causality. Therefore, we conducted a second study that manipulated participants' expectancies regarding an upcoming interethnic interaction. The study used a design drawn from previous work examining the implications of people's response expectancies for their responses in Black/White interactions (Butz \& Plant, 2006). Specifically, participants were provided with feedback indicating that their partner for an upcoming interethnic interaction was not open to the interaction and was anticipating the participant to be biased against the partner's ethnic group. We then examined the participants' emotional responses and desire to avoid the upcoming interaction, as well as their tendency to blame their partner if the interaction went poorly. An examination of other-directed blame in interethnic interactions was included in the current study because theoretical and empirical work indicates that anger and other-directed blame are closely connected and may share a common source (Leary \& Atherton, 1986; Weiner, 1995). Consistent with this possibility, Butz and Plant (2006) demonstrated that both anger and blame directed at racial outgroup members stemmed from negative response expectancies. Blaming ethnic outgroup members may not only have negative implications for current interethnic interactions but may also serve as justification for avoiding future interethnic interactions.

Based on Butz and Plant's (2006) work with Black/White interactions, we anticipated that participants' primary emotional reaction to the response expectancy feedback would be anger as opposed to anxiety. In addition, consistent with Study 1, it was possible that the White participants would respond more strongly to the response expectancy feedback and report heightened anger compared with the Hispanic participants. Consistent with previous work (Butz \& Plant, 2006), we predicted that the response expectancy feedback would also influence the participants' tendency to blame their partner if the interaction did not go well.

We also anticipated that the current study would replicate the findings regarding avoidance from Study 1 . The fact that anger led to avoidance particularly for the White participants in Study 1 is consistent with these participants not feeling that they should act out on their anger due to either personal or societal standards, discouraging overt bias particularly toward disadvantaged social groups. If this were the case, then we would anticipate anger to be a stronger predictor of avoidance for the White participants than the Hispanic participants. By contrast, because Hispanic people tend to have less power in the USA, feelings of anxiety should be more strongly associated with avoidance for the Hispanic than the White participants.

\section{Method}

Participants and design Participants were 41 White and 31 Hispanic introductory psychology students who volunteered to take part in the study as partial fulfillment of a course requirement $(58 \%$ female; $M$ age $=19.14, S D=1.44)$. The study had a 2 (ethnicity of participant: Hispanic vs. White) $\times 3$ (response expectancy feedback condition: Positive vs. Negative vs. None) between-participants factorial design. ${ }^{3}$

Procedure Participants signed up for experimental sessions on online signups requesting either 'White non-Hispanic' or 'Hispanic' participants. ${ }^{4}$ Upon arriving at the laboratory, participants were informed that the experiment investigated people's responses to interactions and that they had been assigned to participate in an interethnic interaction with a same-sex person who was currently working with an experimenter in another room. White participants were told that they would be meeting with a Hispanic student, whereas Hispanic participants were told that they would meet with a White student. Participants were also notified that they would be completing several questionnaire packets prior to meeting their partner, the first of which contained either the Attitudes Toward Hispanics scale for White participants $(\alpha=.94)$ or the Attitudes Toward Whites scale for Hispanic participants $(\alpha=.90)$. Items on these scales were identical to those used in Study 1.

The procedure for the manipulation of response expectancies was similar to the 
procedure employed by Butz and Plant (2006), who manipulated White and Black participants' response expectancies for interracial interactions. Participants completed a questionnaire that assessed their openness to participating in an interethnic interaction. Participants in the response expectancy feedback conditions then received a questionnaire ostensibly completed by their interaction partner implying that he or she was either open or not open to interethnic interactions and either did not expect or expected bias from the participant. Participants were instructed to take a few minutes to read over their partner's answers. The responses on this questionnaire served as the manipulation of response expectancies (see description in Materials). Participants in the control condition filled out the same measures prior to the alleged interaction, but did not anticipate receiving information about their partner's prior interracial experiences (for a complete description of the manipulation, see Butz \& Plant, 2006).

Participants in all conditions then completed a questionnaire packet containing measures of their expectancies, emotions (e.g. anger, anxiety), desire to avoid the interaction, and the degree to which they would externalize blame to their partner for a negative interaction. Finally, participants were informed that the experiment had concluded and there would not be an interaction, after which they were probed for suspicion, fully debriefed, given credit, and excused.

Materials As part of the response expectancy manipulation, participants completed an interaction background questionnaire that assessed their openness to participating in an interethnic interaction and the extent to which they were anticipating biased treatment in the interaction. For example, this questionnaire included items such as 'I expect my partner to be biased toward me in the interaction' rated on a 1 (not at all) to 7 (very much) scale.

Participants in the positive response expectancy condition received their ostensible partner's completed interaction background questionnaire with the responses indicating that their partner anticipated a positive interaction and was not expecting to be treated with bias. Participants in the negative response expectancy condition received a questionnaire completed in a manner indicating that the other person anticipated a negative interaction and was expecting biased treatment during the interaction. After receiving the response expectancy feedback (or not in the no feedback group), participants completed a measure of their response expectancies about the upcoming interaction. The response expectancy items were specifically included as a check of the response expectancy manipulation. Nine items (e.g. 'I am concerned that my partner expects me to be prejudiced') were averaged and reverse-coded where necessary to form an index of response expectancies where higher scores indicated more negative expectancies $(\alpha=.94)$.

Participants then completed a questionnaire assessing their emotional responses to the upcoming interaction by responding to a series of emotion descriptors using 1 (does not apply at all) to 7 (applies very much) scales. To form an index of anxiety, five items (e.g. anxious, nervous, uneasy, concerned, uncertain; $\alpha=.84$ ) were averaged with higher numbers indicating greater anxiety. An anger index was formed by averaging five items (e.g. angry, hostile, irritated, agitated, resentful; $\alpha=.93$ ), with higher numbers indicating more anger.

Finally, participants completed a questionnaire that assessed their avoidant intentions regarding the upcoming interaction (e.g. 'I wish I could avoid having this interaction'; $\alpha=.85$ ). Items were rated on a scale of 1 (strongly disagree) to 7 (strongly agree). Four items assessed participants' externalization of blame (i.e. blaming their partner) for a negative interaction. Items on this other-directed blame scale included 'If this interaction doesn't go well, it will be my partner's fault' $(\alpha=.86)$. On both scales, items were averaged to create indices with higher numbers indicating greater avoidance and blame.

\section{Results}

As in Study 1, participants' responses to the indices were analyzed using hierarchical regression. All continuous measures were $z$-scored 
for the analyses. Similar to our previous work (Butz \& Plant, 2006), across the analyses the positive feedback conditions and the no feedback conditions did not differ. Therefore, for all of the reported analyses, we combined these conditions and focused on the effect of negative feedback compared with positive or no feedback. As a first step in the analysis, we explored whether the response expectancy feedback influenced participants' response expectancies and whether the influence was similar for the Hispanic and White participants. Specifically, for the first step of the regression, we examined the implications of response expectancy feedback, ethnicity, and attitudes toward outgroup members for response expectancies regarding interethnic interactions. For the second step of the regression, we examined the interaction between the participants' ethnicity and the response expectancy feedback.

The manipulation check was successful. Specifically, participants who received negative feedback reported more negative response expectancies than participants who received positive or no feedback, $F(1,68)=122.78, p<.001$, $\beta=-.78$. Consistent with Study 1, participants' response expectancies were also related to their attitudes toward the outgroup such that participants with more negative attitudes toward the outgroup expected that outgroup members were not open to interacting with them, $F(1$, $68)=13.90, p<.001, \beta=.29$.

We next examined the implications of response expectancy feedback, ethnicity, and attitudes toward outgroup members for participants' anxiety and anger regarding the upcoming interaction. Based on Study 1 and our previous work, we predicted that the response expectancy feedback would influence the participants' anger but not their anxiety. In addition, it was possible that the feedback would only influence the degree of anger for the White participants but not the Hispanic participants.

Consistent with previous findings on White/ Black interactions, the analysis of anger revealed that participants who received negative feedback reported more anger regarding the upcoming interaction than the other participants, $F(1,68)=9.66, p<.004, \beta=-.35$ (Figure 2) Participants' attitude toward the outgroup was also related to their anger about the interaction such that participants with more negative

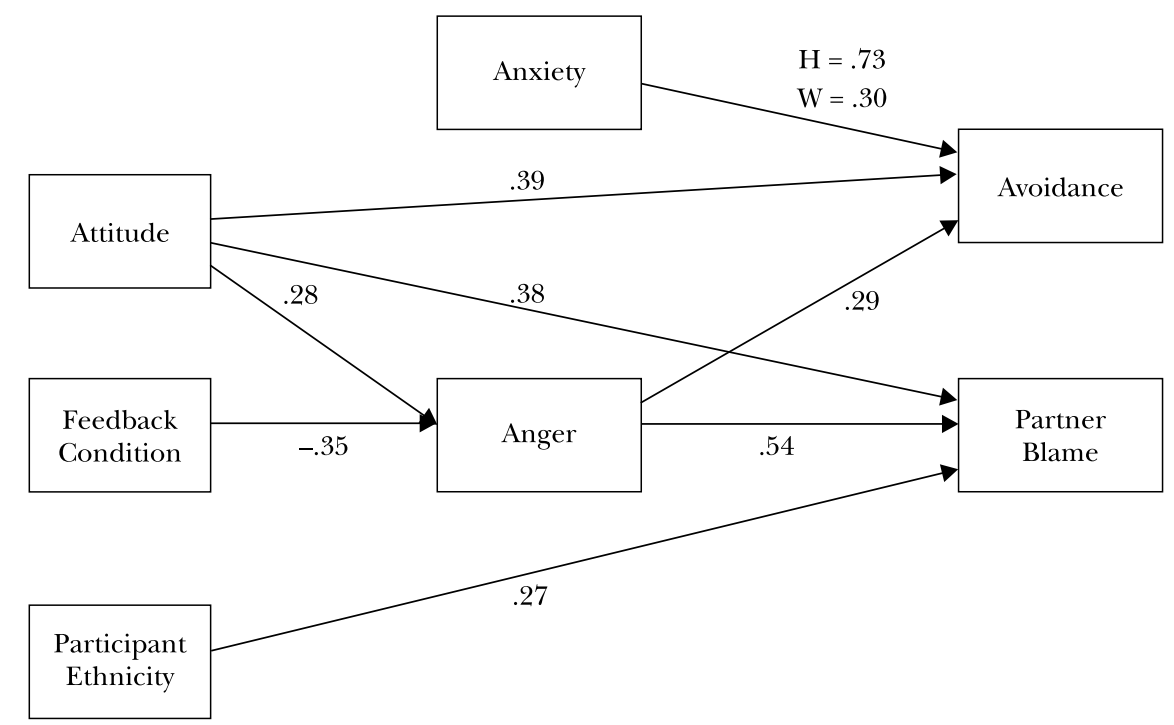

Figure 2. White and Hispanic participants' responses (Study 2). All included paths were significant at $p<.05$. H, Hispanic participants; W, White participants. Participant ethnicity coded $0=$ Hispanic, $1=$ White. 
attitudes toward the outgroup were more angry about the upcoming interaction, $F(1,68)=5.14$, $p<.03, \beta=.28$. For the analysis of anxiety, the response expectancy feedback was not a significant predictor of participants' anxiety about the upcoming interaction, $F(1,68)=2.04$, $p=.16, \beta=-.28$.

Participants' desire to avoid the interaction and tendency to blame their interaction partner were analyzed using hierarchical linear regression. The first step of the analyses included ethnicity of participant, feedback, and attitude. The second step of the analyses included anger and anxiety. The third step included the interactions of ethnicity with feedback condition, anger, and anxiety.

The first step of the analysis for avoidance revealed effects for response expectancy feedback with negative feedback resulting in a stronger desire to avoid the upcoming interaction than the other conditions, $F(1,68)=7.94$, $p<.007, \beta=-.29$. Negative attitudes about the outgroup also resulted in a stronger desire to avoid the upcoming interaction, $F(1,68)=17.87$, $p<.001, \beta=.49$. In the second step of the regression, participants who were anxious about the interaction wanted to avoid it, $F(1,66)=7.06$, $p<.02, \beta=.28$. Consistent with Study 1, participants who were angry about the interaction also wanted to avoid it $F(1,66)=7.33, p<.01$, $\beta=.29$. In addition, in the second step, attitudes continued to predict the desire to avoid $(\beta=.39$, $p<.001)$ but the feedback condition was no longer significant $(\beta=-.11, p=.28)$. These findings provided some evidence that the impact of feedback on avoidance may have been due to anger (note that feedback did not predict anxiety, so it was not a candidate as a mediator). Consistent with this proposition, follow-up analyses indicated that anger mediated the effect of response expectancy feedback on avoidance, Sobel $z=2.05, p<.04$.

Finally, the third step revealed an anxiety by ethnicity interaction, $F(1,63)=5.96, p<.02$, $\beta=-.38$. In order to examine the nature of this interaction, we tested the effect of anxiety on the desire to avoid the interaction for the Hispanic and White participants separately. Whereas anxiety was highly predictive of the desire to avoid interethnic interactions for Hispanic participants $(\beta=.73, p<.002)$, it was moderately predictive for the White participants $(\beta=.30, p<.005)$.

The first step of the analysis for partner blame revealed an effect of participant ethnicity, such that White participants were more likely to blame their partner if the interaction went poorly than were Hispanic participants, $F(1,68)=6.21$, $p<.03, \beta=.28$. Also, there was an effect of response expectancy feedback with negative feedback resulting in more partner blame than the other conditions, $F(1,68)=11.20, p<.002$, $\beta=-.34$. In addition, negative attitudes about the outgroup resulted in participants being more likely to blame their partner if the interaction did not go well than more positive attitudes, $F(1,68)=22.78, p<.001, \beta=.53$.

In the second step of the regression, attitude and ethnicity continued to predict partner blame ( $p$ values $<.05$ ). Feedback condition was also still significant but its impact was much reduced $(\beta=-.19, p=.04)$. In addition, participants who were angry about the interaction reported that they would be more likely to blame their partner than did those who were less angry, $F(1,66)=28.73, p<.001, \beta=.54$. These findings indicate that the effect of the feedback on blame may have been due to its influence on anger. Indeed, a Sobel test indicated that anger partially mediated the effect of response expectancy feedback on blame, Sobel $z=2.65$, $p<.008$. It is worth noting that blame did not mediate the effect of feedback on anger, Sobel $z=1.73, p=.08$.

\section{Discussion}

The current study explored the implications of manipulating participants' response expectancies regarding an upcoming interethnic interaction. Both White and Hispanic participants experienced anger as opposed to anxiety as the primary emotional reaction to the response expectancy feedback indicating that their upcoming interaction partner was not open to interethnic interactions. In addition, those who received negative response expectancy feedback reported that they would blame their partner if the interaction did not go well and that they 
would prefer to avoid the interaction. Mediation analyses indicated that the effects of feedback on partner blame and avoidance were both due to the influence of feedback on anger. These findings highlight the similarity in Hispanic and White people's experiences in interethnic interactions when they anticipate that outgroup members are not open to interacting with them.

Participants' attitudes toward the outgroup also influenced their responses to the upcoming interethnic interaction in a similar manner for the White and Hispanic participants. Both Hispanic and White participants who had negative attitudes about the outgroup reported that they were more angry and irritated about the upcoming interaction and indicated that they would like to avoid the interaction compared with those with more positive attitudes toward the outgroup. More negative intergroup attitudes were additionally associated with intending to blame the interaction partner if the interaction did not go well. These findings indicate that majority and minority group members' negative attitudes toward the outgroup are related to a range of negative responses toward interethnic interactions.

In the current study when participants' response expectancies were manipulated, negative response expectancies were related to anger for both Whites and Hispanics. These findings were somewhat inconsistent with Study 1 where the link between negative response expectancies and anger was relatively stronger for the White participants than the Hispanic participants (although negative response expectancies were robustly related to anger for both groups). However, the current findings are consistent with previous research showing that racial majority and minority group members tend to have similar reactions to response expectancy feedback for interracial interactions about Black and White participants (Butz \& Plant, 2006; Shelton \& Richeson, 2005; Vorauer \& Kumhyr, 2001; Vorauer et al., 1998).

In the current study, the Hispanic and the White participants responded similarly across the measures with two exceptions. First, the White participants reported that they would be more likely to blame their Hispanic interaction partner if the interaction went poorly compared with the Hispanic participants. Although the current data concern blame in interpersonal contexts, they are congruent with Jackson et al.'s (1996) assertion that White people's perceptions of Hispanics may lead to blame due to perceiving them as an economic threat. In interpersonal contexts, externalizing blame to interaction partners may contribute to or strengthen negative expectations centered on the perceived responsiveness of interaction partners. In particular, blaming one's partner for tension or awkwardness in an interaction relative to blaming oneself may bolster negative response expectancies by leading people to expect that outgroup members in future interactions will not be pleasant in interactions. Moreover, such an unwillingness to take responsibility for an unpleasant interaction does not bode well for White participants' future efforts to improve their interethnic interaction skills. Second, consistent with Study 1, in the current study avoidance was more strongly related to anger among the White participants and anxiety among the Hispanic participants. We discuss this finding in more detail later.

\section{General discussion}

Much prior research has examined the factors that determine the course and quality of interracial interactions involving White and Black people. Although Hispanics are now the most populous racial/ethnic group in the USA, comparatively few studies have explored the factors that influence the quality of interactions between White and Hispanic people. The present studies drew upon theorizing about White/Black interactions as well as existing work on interethnic interactions. It examined the role of expectations about intergroup interactions as well as the previous quality of intergroup contact and intergroup attitudes in determining emotions and intentions for interactions between Whites and Hispanics.

Consistent with previous findings regarding White/Black interactions, participants who 
had negative expectations about intergroup interactions reported more negative emotional responses to these interactions. These negative emotional responses, in turn, were associated with negative behavioral intentions such as the desire to avoid interethnic interactions and the externalization of blame if an interethnic interaction did not go well. Also consistent with previous work, in Study 1 Hispanic participants who reported more positive previous interethnic contact also reported more positive self-efficacy and response expectancies. For Hispanic people, pleasant interactions with Whites may translate into greater confidence and less fear of rejection in future interactions with Whites, which may in turn, lead Hispanics to engage in more frequent interethnic interactions. Unlike previous models of White/Black interactions that have shown that quality of previous interethnic contact tends to be associated with more positive expectations for White participants (Plant \& Devine, 2003), the current work revealed that quality of previous contact was not associated with White participants' self-efficacy or response expectancies regarding interactions with Hispanics. This finding suggests that for White people, positive previous experiences with Hispanics may not generalize to future interactions with Hispanics and that White people's expectancies about interactions with Hispanic people may instead come from sources other than actual personal experience.

In contrast to contact, participants' intergroup attitudes represented a factor that was consistently related to expectancies in both studies. Both Hispanic and White participants with more negative attitudes toward the outgroup reported more negative expectations about the openness of outgroup members to interethnic interactions and their own efficacy to perform well in interethnic interactions (Study 1). These findings suggest that attitudes toward Hispanics rather than the quality of previous contact with Hispanics may be the primary predictor of White participants' expectations about interactions with Hispanics. In addition, in Study 2 negative attitudes predicted anger, avoidance, and blame over and above the manipulation of participants' response expectancies. However, because the findings involving attitudes were correlational and the responses were collected at the same time, it is difficult to know whether possessing negative intergroup attitudes results in a negative approach to interethnic interactions or whether negative expectations and responses to interethnic interactions help to shape people's intergroup attitudes. We suspect that the relationship is bi-directional in nature. It will be important to uncover the causality for this relationship in future work. If attitudes influence responses to interactions, then it will be important to focus on changing attitudes when looking to improve intergroup relations. However, if the responses to interactions influence people's attitudes, then working to improve responses to interactions may have the added benefit of improving intergroup attitudes.

The current findings elucidated that White and Hispanic people's reactions to interethnic interactions tended to be generally similar to each other and consistent with responses of Black and White people to interracial interactions. Importantly, however, there was a tendency across both studies for anger to predict White participants' avoidance of Hispanic people but for anxiety to more strongly predict avoidance for Hispanic participants. We posited that White participants perceive it as inappropriate to express their anger through aggression and hostility directed at Hispanic people, who are relatively low in power in the USA. Therefore, instead of anger leading to negative approach-related responses, anger may translate into a desire to avoid interactions with Hispanic people. The findings across the current studies were consistent with these ideas. Among the Hispanic participants, however, the fact that their desire to avoid interactions with Whites was predicted most strongly by anxiety was more consistent with previous intergroup work (Plant, 2004; Plant \& Butz, 2006). Together, these findings speak to the need to understand the breadth of emotional responses to intergroup interactions and the intricacies of different types of intergroup interactions. Previous models of intergroup interactions should be expanded to examine the antecedents and consequences of multiple emotional reactions (see Butz \& Plant, 2006) 
among multiple social groups. In addition, in future work, it would be helpful to directly compare responses to different groups (e.g. White people's responses to Black people and Hispanic people).

\section{Limitations and future directions}

Although the current work provides important insight into the factors that contribute to the quality of interethnic interactions, extensive work is still needed on this issue. In the current studies, we only examined responses to previous or anticipated interethnic interactions. Future work should examine whether our findings apply to actual interethnic interactions between White people and Hispanic people. For example, are White people who report heightened anger about interethnic interactions more likely to exhibit avoidant behaviors when interacting with a Hispanic person and have shorter interactions with Hispanic people than with White people? In addition, although we manipulated participants' response expectancies in Study 2, we did not directly manipulate anger. In future work it would be informative to examine whether a direct anger induction prior to interethnic interactions leads to greater avoidance for White than Hispanic participants. Similarly, does anxiety result in greater avoidance for Hispanic, but not White participants?

In addition to highlighting the factors that may lead to negativity in interethnic interactions, the current findings provide some insight regarding how interethnic interactions may be improved. Clearly, it is essential to improve people's expectations about intergroup interactions in order to improve their responses to these interactions. The findings from Study 1 indicate that positive intergroup contact may help to improve Hispanic people's self-efficacy and response expectancies. Nonetheless, temporal relationships and survey methods did not allow for the strongest test of whether contact increases expectancies. If the current findings hold, then positive interethnic experiences may improve expectancies regarding these interactions. Of course, this creates a bit of circular reasoning: improving intergroup interactions requires engaging in positive intergroup interactions.
In addition, the current findings indicate that positive contact may not improve White people's expectations. It may be possible to boost people's expectancies regarding intergroup interactions through means other than positive contact, such as observing others having positive interactions and reminding people of basic interaction skills. Indeed there is some evidence that observing intergroup friendships or positive intergroup interactions can improve intergroup attitudes (Wright, Aron, McLaughlin-Volpe, \& Ropp, 1997). Additionally, efforts to induce empathic concern for outgroup members may improve people's attitudes about intergroup interactions (Finlay \& Stephan, 2000) and, as a result, lead to more positive expectations about the responsiveness of ethnic outgroup members.

The current findings may shed light on recent debate and legislation in the USA regarding immigration. This study demonstrates that White people who are angry at the prospect of interacting with Hispanics want to avoid such interactions. Restricting immigration and expelling illegal aliens who are Hispanic may be one route of limiting contact with Hispanic people. In addition, several of the items on our Attitudes Toward Hispanics scale tapped into feelings about immigration. It may be that for some Whites, the perception that Hispanics do not belong in the USA is related to beliefs that Hispanics are challenging White privilege and are encroaching upon Whites' physical resources. This threat to the majority group's status and strength may be an important determinant of anger and the avoidance of contact with Hispanics. These possibilities raise several avenues for future research. For example, in future research it will be important to employ a more direct test of whether negative feelings regarding interethnic contact determine support for stricter immigration policy. In addition, it may be informative to explore the specific reasons why negative attitudes toward Hispanics determine anger and avoidance.

\section{Conclusions}

The current work highlights both the similarities and differences in the ways that Whites and 
Hispanics approach interethnic interactions. These findings have both theoretical and practical implications. Theoretically, they add to the growing literature seeking to develop comprehensive models of intergroup interactions that incorporate both majority and minority group members' perspectives. Practically, by elucidating the factors that influence the quality of interethnic interactions, our hope is that this study will help to clarify routes to improve these interactions.

\section{Notes}

1. Six African American and four Asian participants also completed the non-Hispanic version of the questionnaire but because of their small numbers, they were not included in the analyses.

2. The reliabilities for the Hispanic and White samples were highly consistent. The only exceptions were that the anxiety index was more reliable for the White $(\alpha=.79)$ than the Hispanic $(\alpha=.66)$ sample, whereas the anger index was more reliable for the Hispanic $(\alpha=.74)$ than the White $(\alpha=.66)$ sample. Participants also completed a measure of quantity of interethnic contact at the end of the packet. However, as noted previously, quality tends to be a more important factor for intergroup relations than quantity (Brown \& Hewstone, 2005; Eller \& Abrams, 2003; Plant $\&$ Devine, 2003). Indeed, in the current study the quality measure was consistently a stronger predictor than the quantity measure. Therefore, we only used the quality measure for the reported analyses.

3. The current study did not manipulate whether participants anticipated an intragroup interaction or an intergroup interaction. However, as noted previously, Butz and Plant (2006) found that negative response expectancies predicted anger for interracial interactions but not same race interactions. Although that work focused on Black/White interactions, it provides some evidence that response expectancies are relatively more influential for responses in intergroup interactions than in intragroup interactions.

4. To decrease participants' suspicion, the online sign-ups targeted participants' ethnicity in order to make it seem as though the experimenter was aware of participants' ethnicity prior to their arrival (and therefore, could have arranged an interethnic interaction).

\section{References}

Britt, T. W., Boniecki, K. A., Vescio, T. K., Biernat, M., \& Brown, L. M. (1996). Intergroup anxiety: A person $\times$ situation approach. Personality and Social Psychology Bulletin, 22, 1177-1188.

Brigham, J. C. (1993). College students' racial attitudes. Journal of Applied and Social Psychology, 23, 1933-1967.

Brown, R., \& Hewstone, M. (2005). An integrative theory of intergroup contact. In M. P. Zanna (Ed.), Advances in experimental social psychology (Vol. 37, pp. 255-343). San Diego, CA: Academic Press.

Butz, D. A., \& Plant, E. A. (2006). Perceiving outgroup members as unresponsive: Implications for approach-related emotions, intentions, and behavior. Journal of Personality and Social Psychology, 91, 1066-1079.

Cottrell, C. A., \& Neuberg, S. L. (2005). Different emotional reactions to different groups: A sociofunctional threat-based approach to 'prejudice'. Journal of Personality and Social Psychology, 88, 770-789.

Devine, P. G., Evett, S. R., \& Vasquez-Suson, K. A. (1996). Exploring the interpersonal dynamics of interracial context. In R. M. Sorrentino \& E. T. Higgins (Eds.), Handbook of motivation and cognition: The interpersonal context (Vol. 3, pp. 423-464). New York: Guilford Press.

Eller, A., \& Abrams, D. (2003). 'Gringos' in Mexico: Cross-sectional and longitudinal effects of language school-promoted contact on intergroup bias. Group Processes $\mathcal{E}$ Intergroup Relations, 6, 55-75.

Finlay, K. A., \& Stephan, W. G. (2000). Improving intergroup relations: The effects of empathy on racial attitudes. Journal of Applied Social Psychology, 30(8), 1720-1737.

Frey, F. E., \& Tropp, L. R. (2006). Being seen as individuals versus as group members: Extending research on metaperception to intergroup contexts. Personality and Social Psychology Review, 10, 265-280.

Gudykunst, W. B. (1993). Toward a theory of effective interpersonal and intergroup communication: An anxiety/uncertainty management perspective. In R. L. Wiseman \& J. Koester (Eds.), Intercultural communication theory (pp. 8-58). Thousand Oaks, CA: SAGE. 
Harmon-Jones, E. (2003). Anger and the behavioral approach system. Personality and Individual Differences, 35, 995-1005.

Jackson, L. A., Hodge, C. N., Gerard, D. A., Ingram, J. M., Ervin, K. S., \& Sheppard, L. A. (1996). Cognition, affect, and behavior in the prediction of group attitudes. Personality and Social Psychology Bulletin, 22(3), 306-316.

Joyner, K., \& Kao, G. (2000). School racial composition and adolescent racial homophily. Social Science Quarterly, 81(3), 810-825.

Keltner, D., Gruenfeld, D. H, \& Anderson, C. (2003). Power, approach, and inhibition. Psychological Review, 110, 265-284.

Leary, M. R., \& Atherton, S. C. (1986). Self-efficacy, social anxiety, and inhibition in interpersonal encounters. Journal of Social and Clinical Psychology, 4, 256-267.

MacCallum, R. C., Browne, M. W., \& Sugawara, H. M. (1996). Power analysis and determination of sample size for covariance structure modeling. Psychological Methods, 1, 130-149.

Mackie, D. M., Devos, T., \& Smith, E. R. (2000). Intergroup emotions: Explaining offensive action tendencies in an intergroup context. Journal of Personality and Social Psychology, 79, 602-616.

Marin, G. (1984). Stereotyping Hispanics: The differential effect of research method, label, and degree of contact. International Journal of Intercultural Relations, 8, 17-27.

Plant, E. A. (2004). Responses to interracial interactions over time. Personality and Social Psychology Bulletin, 30, 1458-1471.

Plant, E. A., \& Butz, D. A. (2006). The causes and consequences of an avoidance-focus for interracial interactions. Personality and Social Psychology Bulletin, 32, 833-846.

Plant, E. A., \& Devine, P. G. (2003). The antecedents and implications of interracial anxiety. Personality and Social Psychology Bulletin, 29, 790-801.

Plant, E. A., \& Devine, P. G. (1998). Internal and external motivation to respond without prejudice. Journal of Personality and Social Psychology, 175, 811-832.

Ridgeway, C. L., \& Johnson, C. (1990). What is the relationship between socioemotional behavior and status in task groups? American Journal of Sociology, 95, 1189-1212.

Shelton, J. N. (2003). Interpersonal concerns in social encounters between majority and minority group members. Group Processes E Intergroup Relations, 6, 171-185.
Shelton, J. N., \& Richeson, J. A. (2005). Intergroup contact and pluralistic ignorance. Journal of Personality and Social Psychology, 88, 91-107.

Stephan, W. G., \& Stephan, C. W. (1985). Intergroup anxiety. Journal of Social Issues, 41, 157-175.

Stephan, W. G., \& Stephan, C. W. (1989). Antecedents of intergroup anxiety in Asian-Americans and Hispanic-Americans. International Journal of Intercultural Relations, 13, 203-219.

Stephan, W. G., \& Stephan, C. W. (2000). Reducing prejudice and discrimination. In S. Oskamp (Ed.), The Claremont symposium on applied social psychology (pp. 23-45). Mahwah, NJ: Erlbaum.

U.S. Census Bureau. (2005, June). Hispanic Population Passes 40 Million, Census Bureau Reports. (CB05-77). Available <http://www. census.gov/PressRelease/www/releases/ archives/population/005164.html>

Vorauer, J. D., Main, K. J., \& O'Connell, G. B. (1998). How do individuals expect to be viewed by members of low status groups? Content and implications of meta-stereotypes. Journal of Personality and Social Psychology, 75, 917-937.

Vorauer, J. D., \& Kumhyr, S. M. (2001). Is this about you or me? Self-versus other-directed judgments and feelings in response to cross-group interaction. Personality and Social Psychology Bulletin, 27, 706-719.

White, T. J., \& Sedlacek, W. E. (1987). White student attitudes toward Blacks and Hispanics: Programming implications. Journal of Multicultural Counseling and Development, 15(4), 171-183.

Weiner, B. (1995). Inferences of responsibility and social motivation. In M. Zanna (Ed.), Advances in experimental social psychology (pp. 1-47). San Diego, CA: Academic Press.

Wright, S. C., Aron, A., McLaughlin-Volpe, T., \& Ropp, S. A. (1997). The extended contact effect: Knowledge of cross-group friendships and prejudice. Journal of Personality and Social Psychology, 73, 73-90.

Zinner, L. R., Brodish, A. B., Devine, P. G., \& Harmon-Jones, E. (2008). Anger and asymmetrical frontal cortical activity: Evidence for an anger-withdrawal relationship. Cognition and Emotion, 22, 1081-1093.

Paper received 25 July 2006; revised version accepted 31 July 2007. 


\section{Biographical notes}

E. ASHBY PLANT is an associate professor of psychology at Florida State University. She earned her PhD in social psychology from the University of Wisconsin-Madison in 2000. Her research interests include intergroup interactions, the motivation to respond without prejudice, and the regulation and reduction of prejudice.

DAVID A. BUTZ is a postdoctoral fellow in the psychology of peace and violence concentration at the University of Massachusetts, Amherst. He earned his PhD in social psychology from Florida State University in 2007 . His research interests include intergroup interactions, collective identity, and approaches to reduce intergroup conflict.

MARGARITA TARTAKOVSKY earned her MS in clinical psychology from Texas A\&M University in December 2006, where she conducted research on body image and disordered eating. She received her BS in psychology from Florida State University. She is a freelance writer and editor, focusing on psychology and women's issues.

\section{Appendix}

\section{Study 1 Measures}

\section{Positive previous contact}

1. In the past, my experiences with Hispanic people have been pleasant.

2. I have had many positive experiences with Hispanic people.

3. Over the course of my life, I have had many Hispanic friends.

\section{Self-efficacy}

1. I am unsure how to behave toward a Hispanic person in order to convey a nonprejudiced impression.

2. When interacting with a Hispanic person, I would be unsure how to act in order to show him or her that I am not prejudiced.

3. I am confident that I can respond without prejudice when interacting with a Hispanic person.

4. Sometimes stereotypes come to my mind when interacting with a Hispanic person, even when I wish they wouldn't.

5. When interacting with a Hispanic person, I would think a lot about the fact that the other person is Hispanic.
6. I believe that in some ways, interacting with a Hispanic person is more difficult than interacting with a White person.

\section{Response expectancy}

1. Even if we hadn't met before, a Hispanic person would expect me to be prejudiced.

2. When interacting with a Hispanic person, he or she would see me as prejudiced no matter what I did.

3. If I were interacting with a Hispanic person, regardless of my behavior he or she would interpret me as prejudiced.

4. When interacting with a Hispanic person, I would imagine that he or she would be watching my behavior closely for prejudice.

5. Hispanic people do not look for prejudice in White people's behavior.

6. Sometimes Hispanic people view normal behavior of Whites as prejudiced.

\section{Anxiety}

1. I get anxious when interacting with a Hispanic person.

2. I would feel awkward when interacting with a Hispanic person.

3. I would feel uncomfortable when interacting with a Hispanic person.

4. When interacting with a Hispanic person, I would feel relaxed.

5. When interacting with a Hispanic person, I would feel nervous.

\section{Anger}

1. I would find interacting with a Hispanic person frustrating.

2. I would find interacting with a Hispanic person annoying.

3. Interacting with a Hispanic person would be irritating.

\section{Avoidance}

1. If I had a choice, I would rather not interact with a Hispanic person.

2. If I can avoid interacting with Hispanic people, I do.

3. I would look forward to interacting with Hispanic people.

4. I like interacting with Hispanic people.

5. I would want to avoid interacting with a Hispanic person. 


\section{Attitudes Toward Hispanics scale}

Please indicate your agreement/disagreement with each of the following statements, using the scale below. Please write your rating in the blank to the left of each statement.

$\begin{array}{lllllllc}1 & 2 & 3 & 4 & 5 & 6 & 7 \\ \begin{array}{l}\text { Strongly } \\ \text { Disagree }\end{array} & & & & & \begin{array}{c}\text { Strongly } \\ \text { Agree }\end{array}\end{array}$

I would rather not have Hispanics live in the same apartment building that I live in.

I would not mind at all if a Hispanic family with about the same income and education as me moved in next door. ( $\mathrm{R}$ )

It would not bother me if my new roommate were Hispanic. (R)

Stricter laws should be established to control Hispanic immigration.

If a Hispanic were put in charge of me, I would not mind taking advice and direction from him or her. (R)

I would probably feel somewhat self-conscious dancing with a Hispanic person in a public place.

Many Hispanics don't seem interested in becoming friends with individuals outside of their ethnic group.

Hispanic immigrants are demanding too much too fast in their push for equal rights.

It seems to me that Hispanics are unwilling to assimilate into American culture.

If I had a chance to introduce Hispanic visitors to my friends and neighbors, I would be pleased to do so. ( $\mathrm{R})$

Areas such as Miami and California are becoming too Hispanic.

Generally, Hispanics are not as smart as Whites.

Some Hispanics are overly proud of their culture.

It is likely that Hispanics will bring drugs and violence to neighborhoods when they move in.

Some Hispanics are so touchy about their ethnicity that it is difficult to get along with them.

I worry that in the next few years I may be denied my application for a job or a promotion because of preferential treatment given to minority group members.

We shouldn't allow so many Hispanic immigrants to enter the U.S.

I would feel uncomfortable being the only nonHispanic in a room full of Hispanic individuals.

Hispanic men seem more aggressive than the average White male.
From my experiences with Hispanics, I find that they uphold the stereotypes for the most part.

There are too many Hispanic immigrants in this country.

Hispanic people are generally lazy.

It bothers me when Hispanics insist on speaking their own language in public.

Hispanic immigrants are enjoying too many privileges under U.S. law.

I would not want to live in a predominately Hispanic neighborhood.

Many Americans are unable to get jobs because so many Hispanic immigrants are taking them.

Too much tax money is going toward unnecessary funding for Hispanics.

Hispanics are often troublemakers.

It seems to me that Hispanics usually prefer to interact with members of their own ethnic group than with people from other ethnic groups.

Attitudes Toward Whites scale

Please indicate your agreement/disagreement with each of the following statements, using the scale below. Please write your rating in the blank to the left of each statement.

$\begin{array}{cccccccc}1 & 2 & 3 & 4 & 5 & 6 & 7 \\ \begin{array}{c}\text { Strongly } \\ \text { Disagree }\end{array} & & & & & \begin{array}{c}\text { Strongly } \\ \text { Agree }\end{array}\end{array}$

I would not accept an invitation to a New Year's Eve party given by a White couple in their own home.

Many Whites are close-minded about other cultures.

I would rather live in an all-Hispanic neighborhood.

Many Whites don't understand the Hispanic culture.

Most Whites fear Hispanics will bring violence to neighborhoods when they move in.

I don't have much in common with Whites.

Whites often assume the worst about Hispanics.

I feel more comfortable interacting with Hispanics than with White people.

Many Whites have incorrect perceptions of Hispanics.

Most Whites can't be trusted to deal honestly with Hispanics.

Many Whites are not accepting of Hispanics.

Most Whites can't understand what it is like to be Hispanic.

I would rather be friends with a Hispanic individual that a White individual.

Many Whites are too judgmental regarding Hispanics.

I feel closer to people of my own culture than to Whites. 
I feel that Whites often misunderstand Hispanics. I feel that many Whites are arrogant.

Many Whites are biased toward Hispanics.

\section{Study 2 Measures}

Response expectancies

1. I am concerned that my partner expects me to be prejudiced.

2. I think my interaction partner is open to interacting with me.

3. I expect my interaction partner will view me as prejudiced no matter what I do.

4. I anticipate that my interaction partner is biased against people of my ethnicity.

5. My partner will expect me to be biased toward him/her during the interaction.

6. Stereotypes about my ethic group will affect how my partner views me.

7. I expect that my partner won't like me due to my ethnicity.

8. Regardless of my behavior, my interaction partner will view me as prejudiced.

9. I expect that my interaction partner will look for reasons not to like me.

\section{Avoidance}

1. If given the option, I would avoid having this interaction.

2. I wish I did not have to participate in this interaction.

3. I wish I could avoid having this interaction.

4. If I knew ahead of time that this was the person I would be interacting with, I would have cancelled this experiment.

5. If there was another task that I could do instead of having this interaction, I would be interested in hearing more about it.

6. I am looking forward to meeting my partner.

\section{Partner blame}

1. If this interaction doesn't go well, it will be my partner's fault.

2. I will blame my partner if our interaction is unpleasant.

3. If this interaction doesn't go well, it will be because of something the other person said or did.

4. If I had a different partner, I'm sure the interaction would be better. 